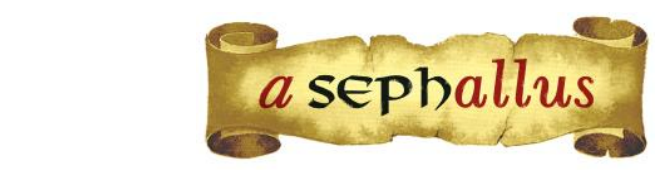

Revista aSEPHallus de Orientação Lacaniana

Núcleo Sephora de Pesquisa sobre o Moderno e o Contemporâneo

ISSN $1809-709$ X

\title{
Estruturas clínicas e metodologia da pesquisa em psicanálise
}

Tania Coelho dos Santos

Pós-doutorado no Departamento de Psicanálise de Paris VIII Professor Associado, nível IV no Programa de Pós-graduação em Teoria Psicanalítica/UFRJ (Rio de Janeiro, Brasil). Pesquisadora do CNPQ nível $1 \mathrm{C}$

Presidente do Instituto Sephora de Ensino e Pesquisa de Orientação Lacaniana/ ISEPOL Psicanalista Membro da École de La Cause Freudienne, da Escola Brasileira de Psicanálise e da Associação Mundial de Psicanálise, Membro da Associação Universitária de Pesquisa em Psicopatologia Fundamental (Rio de Janeiro, Brasil) E-mail: taniacs@openlink.com.br

Este número de aSEPHallus se destaca pela sua clara articulação à pesquisa. Abrimos nossa seleção de trabalhos com a primorosa conferência do colega Jean-Claude Maleval, professor e orientador de pesquisas na Universidade de Rennes, onde se dedica a ressaltar a particularidade da estrutura autista. Ele apresenta a noção de estrutura subjetiva autística, ressaltando que foi introduzida por Rosine e Robert Lefort nos anos 1990 e caracterizada pela ausência de alienação significante, de lalíngua, de S1 e de objeto $a$. Estas indicações são ainda objeto de debate atualmente pois, para apreender a complexidade da clínica do espectro autista, estes autores só dispunham da noção de divisão do sujeito no real do duplo. Hoje em dia parece possível apreender a estrutura autista a partir de características maiores, tais como: uma retenção inicial dos objetos pulsionais; uma alienação retida, que se opera sem a dobradiça do significante-mestre; uma aparelhagem do gozo pela borda.

Também eu, Tania Coelho dos Santos, trouxe um relato que fiz durante o último Congresso da Associação Universitária de Pesquisa em Psicopatologia Fundamental da minha experiência como professora e orientadora no Programa de Pós-Graduação em Teoria Psicanalítica. Intitulei o relato de: "A clínica reorientada pela pesquisa na pós-graduação". A realidade de fato do programa me conduziu a ir além da proposta inicial: a pesquisa teórica dos fundamentos epistemológicos desta disciplina. No início, o programa atendeu a demanda de psicanalistas em prática privada de conferir mais densidade teórica e refinamento clínico às suas respectivas formações em institutos, escolas e sociedades psicanalíticas. Depois dos anos 2000 uma grande quantidade de profissionais que praticam a psicanálise aplicada em instituições públicas tais como, saúde, educação e justiça e, algumas vezes, em instituições privadas chegaram ao nosso curso de mestrado e doutorado com a intenção de repensar suas práticas à luz da pesquisa rigorosamente conduzida em conformidade com a teoria da clínica psicanalítica. Ficou demonstrado pela prática da pesquisa que é impossível repensar a teoria sem uma forte e dinâmica relação com os impasses da prática.

Antônio Teixeira, professor e pesquisador no Programa de Pós-Graduação da UFMG, por sua vez, trouxe uma excelente reflexão acerca de: "O modelo e o exemplo na nosologia psicanalítica". Ele resume assim seu ponto de vista: diversamente do modelo nosológico que opera com um saber sobre a patologia do indivíduo, o recurso ao exemplo nos auxilia a pensar a 
condução clínica como uma prática guiada pelo saber construído pelo próprio sujeito em sua experiência de vida. É por isso que no lugar da simplificação homogênea do modelo, o autor ensina a valer-se do exemplo como chamado para fazer algo diferentemente igual, no sentido em que uma situação clínica pode ser tomada como paradigmática para se pensar o que cada caso comporta de absolutamente inédito.

Katerine da Cruz Leal Sonoda traz recomendações acerca de o método psicanalítico, as condições da análise e da pesquisa clínica. O objetivo do artigo é apontar para as possibilidades e limites do uso do método psicanalítico em um contexto não clínico, especificando as aproximações e os distanciamentos entre a situação clínica e a situação de pesquisa empírica. Pressupõe que o psicanalista que ocupa o lugar de entrevistador fala de um lugar de poder e de saber que produz efeitos no entrevistado. Com o cuidado de não adotar um estilo "protocolar", mas buscando apresentar sistematicamente as condições mínimas da prática da psicanálise, ela destaca algumas dessas condições. Assim como na clínica, na situação de pesquisa empírica existem dois fenômenos indissociáveis: o que ocorre do lado pesquisado ou analisando; e o que ocorre do lado do pesquisador; ou analista.

Rachel G. Amin Feres de Freitas, seguindo os passos de Jean-Claude Maleval se pergunta se o autismo é uma estrutura a mais. O tema do autismo constitui um campo de estudos relativamente novo. $O$ século XXI, ela recorda, traz uma importante reflexão sobre o autismo e uma pergunta que se impõe aos psicanalistas: temos uma epidemia de autismo ou de diagnóstico de autismo? As pesquisas para saber sobre a causa do autismo são muitas em diferentes abordagens teóricas e evidenciam uma antinomia importante entre indivíduo e sujeito. Ela se pergunta se estaremos enquanto psicanalistas do lado da homogeneização destas crianças ou prontos para a escutá-las em suas diferenças?

José Maurício Teixeira Loures e Maria Helena Martinho em seu artigo acerca da psicanálise selvagem em suas relações com a perversão transitória, interrogam a direção do tratamento em um caso clínico apresentado pela psicanalista francesa Ruth Lebovici. O caso foi publicado originalmente em 1956 e intitula-se "Perversão sexual transitória no decorrer de um tratamento psicanalítico". Esse estudo evidencia os efeitos das interpretações selvagens da analista. As proposições de Freud e de Lacan sobre a interpretação e, mais especificamente, os comentários de Lacan sobre o caso, elucidam os deslizamentos sofridos na técnica psicanalítica.

Vanessa Teixeira dos Santos escreve sobre o crime e a diferença entre os sentimentos de culpa no homem e na mulher. A autora aborda o número de mulheres e de homens que cometem crimes, ressaltando que o índice é em geral maior entre os homens. A partir da noção de Freud e Lacan sobre o crime enquanto busca de um alívio do sentimento de culpa inconsciente pelos desejos de parricídio e incesto através de crimes e punições reais, pretende discutir as diferenças na formação do sentimento de culpa na mulher e no homem. Para tal, discute os caminhos do complexo de Édipo na menina e no menino e propõe que, como a menina passa por este processo de forma diferente, a mulher pode cometer menos crimes. 
Cleyton Andrade, professor da UNIFAL, aborda alguns aspectos das representações sociais, políticas e subjetivas da violência. Formas subjetivas e subjetiváveis da incidência da violência no corpo próprio, no corpo social e político. Com isso procura indicar como ponto de investigação que o encontro dissimétrico entre corpos e entre sujeitos, políticos ou não, ao invés de ser a base para discursos jurídicos, do Direito e de políticas da igualdade, pode na verdade, indicar práticas de dominação e violência, inclusive inscritas no campo da lei e da norma. Em outras palavras, apontar como o discurso do Outro não apenas produz o corpo da histérica, mas corpos que se tornam alvo de políticas públicas de confronto com um inimigo.

Patrícia Matos Rodrigues, em "Mal-estar na feminilidade: "Filhos... filhos? Melhor não têlos! Mas se não os temos, como sabê-los? Lembra que Freud acreditava que o desejo de ter um filho caracterizava a posição feminina: a herança do útero. "Ser mãe" era um semblante simples e natural. Porém, esse semblante deixou de ser uma evidência lógica. A ciência e o direito modificaram o desejo de ter um filho. De acordo com Coelho dos Santos, os progressos técnicos em torno da procriação e os direitos sociais regulamentados pelos estatutos das mulheres e dos homossexuais emanciparam o desejo de ter um filho das relações com o outro sexo e dos limites da natureza. Vivenciamos a disjunção entre a identificação sexual e as funções de pai e de mãe. Nessas novas configurações familiares, as diferenças se apagam e o termo "cuidador" ganha valor. Um "cuidador" é um "pai-mãe", o que reduz a "um" as funções parentais. Diante desse panorama, que exibe impasses entre uma posição conservadora ou revolucionária na cena social, pretendemos interrogar qual seria a função do psicanalista nesse cenário e com que princípios teóricos ele deve operar.

Em todos esses artigos encontramos a marca de uma pesquisa conduzida pelos princípios e a metodologia psicanalíticos. Agradecemos a todos os autores que contribuíram para mais um numero que esperamos, vai alcançar pleno êxito em agradar o nosso leitor. Vamos aguardar as repercussões.

Tania Coelho dos Santos

Editora de aSEPHallus Revista de Orientação Lacaniana.

Citacão/Citation: Dos Santos, T. C. (mai. 2018 a out. 2018). Estruturas clínicas e metodologia da pesquisa em psicanálise. Revista aSEPHallus de Orientação Lacaniana, 13(26), 1-3. Disponível em www.isepol.com/asephallus. Doi: 10.17852/1809-709x.2019v13n26p1-3.

Editor do artigo: Tania Coelho dos Santos.

Recebido/Received: 03/01/2019 / 01/03/2019.

Aceito/Accepted: $12 / 03 / 2019$ / 03/12/2019.

Copyright: (C) 2019 Associação Núcleo Sephora de Pesquisa sobre o moderno e o contemporâneo. Este é um artigo de livre acesso, que permite uso irrestrito, distribuição e reprodução em qualquer meio, desde que o autor e a fonte sejam citados/This is an open-access article, which permites unrestricted use, distribution, and reproduction in any medium, provided the author and source are credited. 